\title{
Ceramides metabolism and impaired epidermal barrier in cutaneous diseases and skin aging: focus on the role of the enzyme PNPLA1 in the synthesis of $\omega$-O-acylceramides and its pathophysiological involvement in some forms of congenital ichthyoses $^{\text {th }}$
}

\author{
Nathalie Jonca* \\ Unité Différenciation Epithéliale et Autoimmunité Rhumatoïde (UDEAR), UMR 1056 Inserm-Université Toulouse 3, Place du Dr \\ Baylac, Hôpital Purpan, TSA 40031, F-31059 Toulouse Cedex 9, France
}

Received 11 February 2019 - Accepted 18 March 2019

\begin{abstract}
The outermost layer of the skin, the stratum corneum, is essential for the protective barrier functions of the skin. It results from the stacking of corneocytes, the dead flattened cells resulting from epidermal terminal differentiation of underlying living keratinocytes. The cornified lipid envelope, encapsulating corneocytes, and the extracellular mortar-like multilayered lipid matrix, called lamellae, are two crucial elements of the epidermal barrier. Stratum corneum extracellular lipids are mainly composed of ceramides, cholesterol and free fatty acids. Ceramides, and more specifically the epidermis specific $\omega$-Oacylceramides, are essential for lipid-matrix organization into lamellae and formation of the corneocyte lipid envelope. Pathophysiological studies of inherited lipid metabolism disorders recently contributed to a better understanding of stratum corneum lipid metabolism. In the lab, our data from patients with Autosomal Recessive Congenital Ichthyosis and a murine knock-out model showed that the enzyme PNPLA1 is essential for the last step of synthesis of omega-O-acylceramides. Skin aging is a complex biological process caused by genetic and extrinsic factors e.g. sun exposure, smoke, and pollution. Aging skin is marked by a senescence-related decline in lipid and water content, which ultimately impairs epidermal barrier function. Thus, aged epidermis is prone to develop altered drug permeability, increased susceptibility to irritants contact dermatitis and severe xerosis. Ceramide deficiency may account, at least in part, for the dysfunction of the stratum corneum associated with ageing. Hence, treatments able to increase skin-ceramide levels could improve the epidermal barrier function in aged skin. Many animal testing and clinical trials are taken in that regard.
\end{abstract}

Keywords: epidermal barrier / ichthyosis / omega-O-acylceramide / PNPLA1 enzyme / skin aging

Résumé - Métabolisme des céramides et altération de la barrière épidermique en pathologie dermatologique et au cours du vieillissement cutané : focus sur le rôle de l'enzyme PNPLA1 dans la synthèse des $\omega$-O-acylcéramides et son implication physiopathologique dans certaines formes d'ichtyoses congénitales. La couche la plus superficielle de la peau ou stratum corneum est essentielle à la fonction de barrière protectrice de la peau. Elle est formée d'un empilement de cornéocytes, cellules mortes aplaties résultant de la différenciation terminale des kératinocytes épidermiques. L'enveloppe cornée lipidique, qui entoure les cornéocytes, et la matrice lipidique extracellulaire multi-lamellaire, appelée lamellae, sont deux éléments cruciaux de la barrière épidermique. Les lipides extracellulaires du stratum corneum sont essentiellement composés de céramides, cholestérol et acides gras libres. Les céramides, et plus particulièrement les $\omega$-O-acylcéramides, sont nécessaires à l'organisation des lamellae et la formation

\footnotetext{
Contribution to the Topical Issue "Lipids in the elderly: needs, nutrition and physiopathology / Les lipides pour les seniors : besoins, alimentation et physiopathologie"

*Correspondence: nathalie.jonca@inserm.fr
} 
de l'enveloppe cornée lipidique. L'étude physiopathologique de maladies héréditaires du métabolisme des lipides a récemment contribué à mieux comprendre le métabolisme des lipides du stratum corneum. Nos données issues de patients atteints d'ichtyose congénitale autosomique récessive et d'un modèle de souris knock-out ont montré que l'enzyme PNPLA1 est essentielle à l'ultime étape de synthèse des $\omega$-Oacylcéramides. Le vieillissement cutané est un processus biologique complexe causé par des facteurs génétiques et extrinsèques (exposition solaire, tabac, pollution...). Au cours du vieillissement, le contenu de la peau en eau et en lipides, incluant les céramides, diminue progressivement ce qui, à terme, affecte la barrière épidermique. Ainsi, la peau âgée a tendance à développer des défauts de perméabilité aux drogues, une sensibilité accrue aux irritants, dermatites de contact et xérose sévère. De nombreux tests sur animaux et essais cliniques sont conduits dans le but d'augmenter le taux de céramides épidermiques et donc d'améliorer la barrière cutanée de la peau âgée.

Mots clés : barrière épidermique / enzyme PNPLA1 / ichtyose / omega-O-acylcéramide / vieillissement cutané

\section{Introduction}

The epidermis is a stratified epithelium consisting mainly of keratinocytes (Fig. 1). These cells differentiate throughout their migration from the basal layer towards the external surface of the skin. At the latest stage, they undergo cornification, a programmed cell death leading to the transformation of granular keratinocytes, the last living cells in the program of keratinocyte terminal differentiation, into corneocyte. Stacking of the corneocytes forms the stratum corneum, the outermost layer of the epidermis. The stratum corneum is essential for the main function of the epidermis, the barrier function, vital for the organism. It mainly fulfils the permeability barrier function by dampening transepidermal loss of water and electrolytes and by preventing entry of toxic or pathogenic agents. An impaired epidermal barrier is associated with numerous skin diseases like atopic dermatitis, psoriasis or rare genodermatoses such as ichthyoses (Castiel-Higounenc et al., 2004; van Smeden et al., 2014). Elderly skin is typically thin and fragile, with increasing susceptibility to bruising and impaired wound healing (Gilchrest, 1996). The stratum corneum and more particularly the stratum corneum lipid structures are expected to undergo significant changes during the course of ageing. However, this has been little studied in comparison to other skin compartment like the dermis.

\section{Epidermal barrier and stratum corneum lipids: importance of $\omega$-O-acylceramides}

Lipids play an important role in the epidermal permeability barrier function. Human stratum corneum lipids consist of $50 \%$ ceramides, $25 \%$ cholesterol, $10-15 \%$ free fatty acids (predominantly long-chain and saturated) and 5\% of other various lipids. Sebaceous glands produce triglycerides, squalene, waxes, cholesterol and free fatty acids that form a hydro-lipid film at the surface of the skin while most components of the lipid-rich extracellular matrix of the stratum corneum are produced by the underlying living keratinocytes from the granular layer. Precursors of these stratum corneum lipids, such as glucosyl(acyl)ceramides, phospholipids and sphingomyelin, are stored in the tubulo-vesicular secretory organelles called lamellar bodies. At the stratum granulosum/ stratum corneum interface, these precursors are released and processed into mature products that assemble into continuous hydrophobic lamellar lipid structures surrounding the corneocytes, the lamellae, or are crosslinked to the cornified envelope of corneocytes to form the cornified lipid envelope (Menon et al., 2012).

Ceramides are sphingolipids resulting from the combination of a fatty acid and a sphingoid base via an amine link. They are the major lipid species in the stratum corneum, where they present a high degree of complexity linked to an important molecular heterogeneity. The sphingoid moiety can be sphingosine (S), dihydrosphingosine (D), phytosphingosine $(\mathrm{P})$ or 6-hydroxy-sphingosine $(\mathrm{H})$. The diversity of epidermal ceramides is additionally enhanced by the huge fatty acid moiety linked in amine position which can be nonhydroxy (N), $\alpha$-hydroxy (A) or ester linked $\omega$-hydroxy (EO) (Tab. 1). There is a high level of $\omega$-hydroxyceramide with ultra-long carbon chain (C28-C38). Two major distinctive classes of ceramides derive from esterification of the $\omega$-hydroxyl group: $\omega$-fatty acid (predominantly linoleic acid) esterified ultra-long chain-ceramides, and protein bound ceramides due to esterification with glutamate side chains of cornified envelope proteins (Jennemann et al., 2012; Rabionet et al., 2014). These two ceramide species are specific to epidermis and are essential for lipid-matrix organization into lamellae and formation of the corneocyte lipid envelope (Menon et al., 2012).

The specific importance of epidermal ceramides has been assigned definitively to their role in maintaining epidermal barrier homeostasis. Numerous enzymes and molecular actors are necessary for the synthesis, transport, secretion and extracellular maturation of all major epidermal ceramides. Most of them have been recently uncovered. In short, esterified and protein-bound ceramides (i.e. ceramides forming the cornified lipid envelope) require starts in late stratum spinosum/early stratum granulosum with the synthesis of $\omega$-hydroxylated ultra-long fatty acids $(\mathrm{C} 28-\mathrm{C} 38)$ at the endoplasmic reticulum, which requires the fatty acid elongase ELOVL4 (Li et al., 2007) and the hydroxylase CYP4F22 (Ohno et al., 2015). After activation, which involves SLC27A4/FATP4 (Herrmann et al., 2005; Moulson et al., 2007), a specialized ceramide synthase, CERS3, condenses the ultra-long $\omega$-hydroxy-fatty acids with sphingoid bases to form $\omega$-hydroxy-(dihydro)ceramides (Jennemann et al., 2012). The transacylase PNPLA1, most probably enhanced by the cofactor ABHD5, allows $\omega$-esterification of ceramides with linoleic acid released from triglycerides (Ohno et al., 2017, 2018). The resulting $\omega$-esterified ceramides then require 


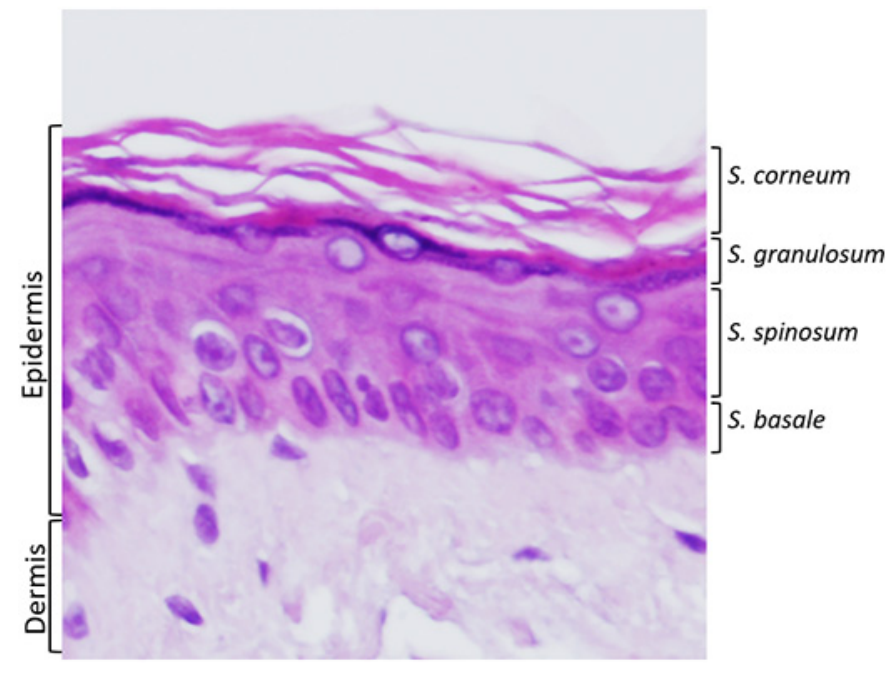

Fig. 1. Histology of normal human epidermis (hemalun-eosin staining).

transport to the Golgi where glucosylation involves the ubiquitously expressed glycosylceramide synthase UGGT to form $\omega$-esterified glucosylceramides, a polar preform of the barrier ceramide (Jennemann et al., 2007). Omega-esterified (glucosyl) ceramides then are packed together with polar precursors of other barrier lipids into lamellar bodies, which requires the $\mathrm{ABC}$ transporter ABCA12 (Smyth et al., 2008). Fusion of lamellar bodies with the plasma membrane by the SNARE-complex may involve the isoform SNAP29 (Schiller et al., 2016). Most of the secreted barrier lipids will form the extracellular lipid lamellae, but some are trans-esterified to proteins of the cornified envelope to form the cornified lipid envelope (Breiden and Sandhoff, 2014). This trans-esterification involves initial oxidation of the $\omega$-bound linoleic acid by 12R-LOX and eLOX3, and finally transglutaminase TGase 1 transfers $\omega$-hydroxy-glucosylceramides onto proteins of the cornified envelope (Krieg et al., 2013). Protein-bound glucosylceramides are processed by glucosylceramidase, an acidic ceramidase, with the help of activator proteins to form protein-bound $\omega$-hydroxy-ceramides and later protein bound $\omega$-hydroxy-fatty acids (Breiden and Sandhoff, 2014; Rabionet et al., 2014) (Fig. 2).

\section{Omega-O-acylceramides and pathophysiological study of ichthyoses: example of the elucidation of PNPLA1 biological role}

Numerous inherited skin diseases directly result from abnormalities in sphingolipids. Identification and characterization of the corresponding genes, as well as the study of the corresponding $\mathrm{KO}$ mouse models, largely contributed to a better knowledge of fundamental aspects of ceramide metabolism (Elias et al., 2008; Borodzicz et al., 2016). This was particularly the case with the pathophysiological study of Autosomal Recessive Congenital Ichthyoses (ARCI), a subgroup of rare monogenic skin diseases due to mutation of genes involved in cornification.
At birth many ARCI patients are "collodion babies", a descriptive term for infant born encased in a tight shiny skin that resembles plastic wrap. Later, the skin phenotype consists in generalized scaling and variable erythroderma, with a wide spectrum of clinical presentations from lamellar ichthyosis to congenital ichthyosiform erythroderma. To date, mutations associated with ARCI have been described in 10 genes: ABCA12, ALOX12B, ALOXE3, CERS3, CYP4F22, NIPAL4, PNPLA1, SDR9C7, SULT2B1 and TGM1. Some of them have been addressed in many works which demonstrated their involvement in stratum corneum lipid metabolism. Recently, our group as well as others showed that PNPLA1 was a key player in the formation of $\omega$-esterified ceramides (Grond et al., 2017; Hirabayashi et al., 2017; Ohno et al., 2017; Pichery et al., 2017).

Patatin-like phospholipase domain containing 1 (PNPLA1) is one of the 9 members of the PNPLA family, characterized by a highly conserved "patatin" domain. These proteins have diverse lipolytic and acyltransferase activities and play a key role in the lipid metabolism(Wilson et al., 2006; Kienesberger et al., 2009). PNPLA1 was the less characterized member of this family. Interest in the biological function of this protein was enhanced by the recent identification of PNPLA1 gene as an ARCI-associated gene, originally in a spontaneous mutant dog model then in patients affected by ARCI for which no mutation in other already known ARCI-causing gene was detected (Grall et al., 2012). However, the enzymatic function of PNPLA1 remained unknown. In human, the protein is expressed in the epidermis, predominantly in the granular layer (Toulza et al., 2007; Grall et al., 2012). The only functional data concerning PNPLA1 arose from the work of Grall and coworkers. Their analyses of triglyceride hydrolase activity and $\left[{ }^{14} \mathrm{C}\right]$-linoleic acid incorporation of normal and PNPLA1-deficient cultured human keratinocytes indicated that PNPLA1 had a role in the metabolism of glycerophospholipid rather than neutral lipids (Grall et al., 2012). Thus, deciphering the biological function of PNPLA1 could allow understanding its physiological role in the epidermis and its pathophysiological implication in ARCI.

In the lab, we searched for PNPLA1 mutations in patients suffering from ARCI from our biological collection. Among 105 patients analyzed, 5 novel PNPLA1 mutations were identified in 5 patients from 3 non-consanguineous Caucasian families. Four of these mutations corresponded to amino acid substitution in the highly conserved patatin domain and the fifth was a frameshift with a premature terminal codon that can be predicted to result either in mRNA decay or in the synthesis of a truncated protein. Thus, all these newly identified mutations were strongly suspected to affect the biological function of the protein. In order to better understand the function of PNPLA1 in the epidermis, we developed Pnplal knockout (KO) mice. Pnpla1 deficiency in mice led to neonatal lethality. Pnplal KO E18.5 embryos and newborns had a thick, taut and shiny skin with a shellacked appearance that led to reduced mobility and thus failure to suckle maternal milk. This "collodion-like" appearance was strongly evocative of the collodion baby observed in humans. Histological examination of the skin revealed an increased number of epidermal living layers (acanthosis) and a thick, compact stratum corneum, consistent with proliferation/differentiation disturbance. This phenotype was associated with impairment in the outside-in and inside-out permeability barrier function. Pnplal-deficient mice lethality 
Table 1. Structure and correspondent nomenclatures of human epidermal ceramides.

\begin{tabular}{|c|c|c|c|c|c|}
\hline & & \multicolumn{4}{|c|}{ Fatty acid moiety } \\
\hline \multirow[b]{3}{*}{ Sphingoid base moeity } & Dihydrosphyngosine (dS) & Cer[NdS] & Cer[AdS] & Cer[OdS] & Cer[EOdS] \\
\hline & Sphingosine $(\mathrm{S})$ & $\mathrm{Cer}[\mathrm{NS}]$ & Cer[AS] & $\mathrm{Cer}[\mathrm{OS}]$ & Cer[EOS] \\
\hline & Phytosphingosine (P) & Cer[NP] & Cer[AP] & Cer[OP] & Cer[EOP] \\
\hline
\end{tabular}

Note: Epidermal ceramides (Cer) are classified into 19 classes depending on their sphingoid base and fatty acid moieties. Ceramide species are additionally defined by fatty acid chain length. Fatty acids [N] and [A] contain C16-C30 whereas fatty acids [O] and [EO] contain C28-36. Ceramides can be glycosylated (not represented) and Cer[OS] can be covalently bound to cornified envelope protein shell. Omega-hydroxyceramide include: Cer[Ods], Cer[OS], Cer[OP], Cer[OH]; omega-O-acylceramide include: Cer[EOds], Cer[EOS], Cer[EOP], Cer[EOH]. Ceramide name in square brackets correspond to the Motta nomenclature (Motta et al., 1993).

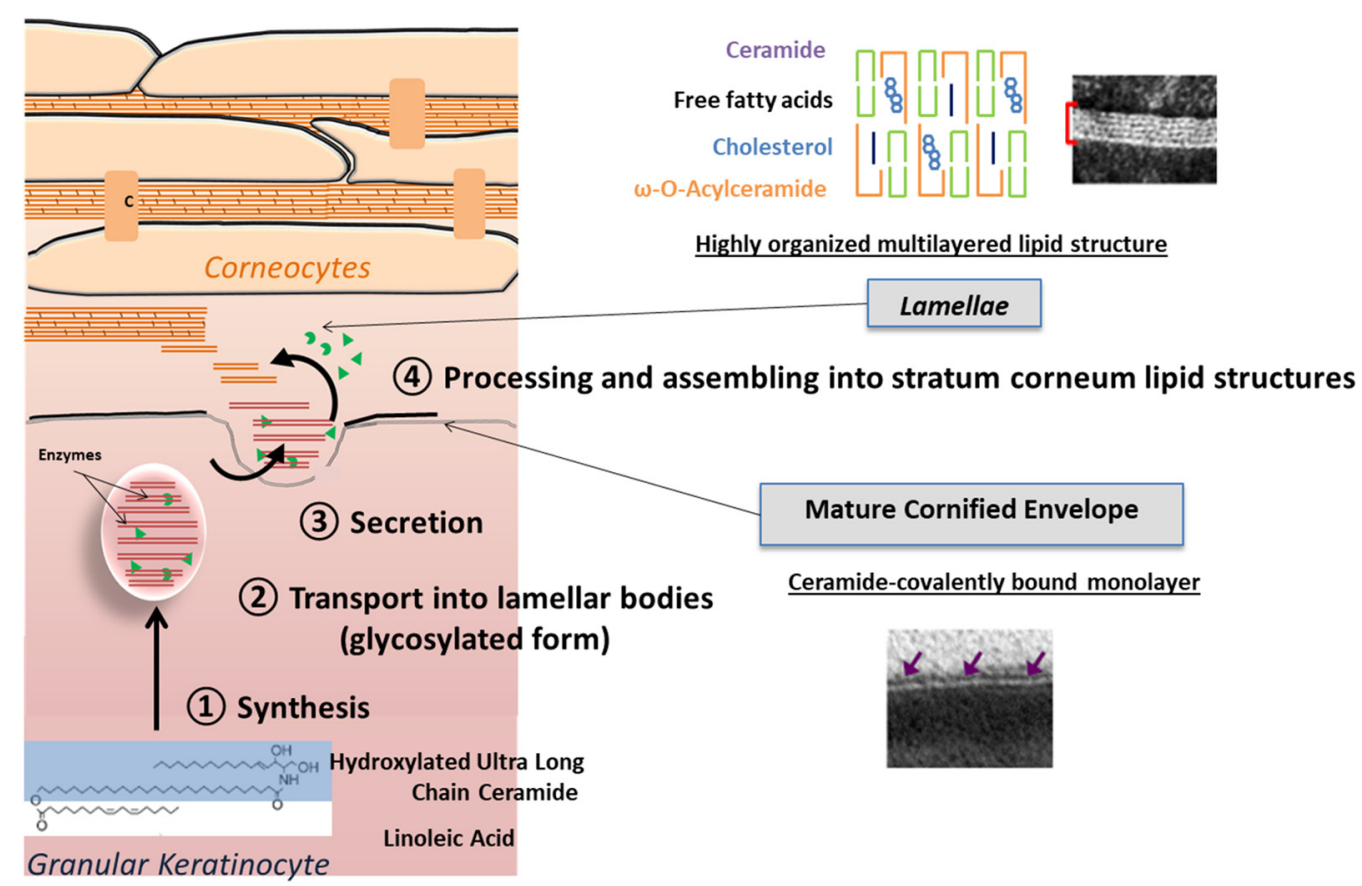

Fig. 2. Omega-O-acylceramide is an epidermis specific sphingolipid with a crucial role for epidermal barrier function.

Diagram showing the synthesis and transport of omega-O-acylceramide in the granular keratinocyte, their secretion at the interface stratum granulosum/stratum corneum and their extracellular processing and assembling into the stratum corneum lipid structures (lamellae and cornified lipid envelope) (see text for details).

was most probably due to severe dehydration caused by both an inability to feed and epidermal barrier impairment. Similar lethal phenotypes have also been reported in mice invalidated for other genes causing ARCI (Matsuki et al., 1998; Epp et al., 2007; Jennemann et al., 2012; Krieg et al., 2013).

Pnpla1-deficient murine skin showed an important alteration in epidermal lipid composition and organization. Ultrastructural analyses of the KO skin by transmission electron microscopy showed an impaired organization of the extracellular lipid matrix in the stratum corneum. Indeed, the typical arrangement in lamellae was observed only in wild-type mice. Moreover, analyses of cornified fluorescent-labelled envelopes showed that when Pnpla1 was absent, cornified envelopes are mainly composed of crosslinked proteins with an obvious defect in lipid coverage (i.e. quasi-absence of cornified lipid envelope). Finally, liquid chromatography coupled to tandem mass spectrometry (LC-MS/MS) revealed that Pnpla1-deficient mice had a modified sphingolipid profile. Quantification of different species of ceramides in the mutant epidermis highlighted a drastic reduction in $\omega$-esterified ceramides with a concomitant accumulation of their metabolic precursors, $\omega$-hydroxyceramides. In accordance with the reduced level of esterified ceramides, we also observed a drastic reduction of their derivatives, the ceramides crosslinked to the cornified envelope, 
relevant with the impaired lipid coverage observed by fluorescence microscopy. These data obtained in mice were confirmed on patients suffering from ARCI. We evidenced in PNPLA1-mutated patients an alteration of the cornified lipid envelope. Moreover, PNPLA1 mutations resulted in an important decrease in stratum corneum esterified ceramides accompanied by an accumulation of its precursors.

Altogether, these results clearly showed that PNPLA1/ Pnplal deficiency provoked a blockade in $\omega$-esterified ceramide synthesis. Pnpla1-deficient mice were developed and analysed by two other groups that reported very similar and concordant results (Grond et al., 2017; Hirabayashi et al., 2017). Furthermore, the work of Kihara's group allowed demonstrating the enzymatic activity of PNPLA1. Indeed, the experiments they performed in vitro or using transfected cell models demonstrated that PNPLA1 was able to transfer linoleic acid from triglyceride to $\omega$-hydroxyceramides (Ohno et al., 2017). In the end, these studies demonstrated that PNPLA1 is a transacylase essential for the synthesis of $\omega$-esterified ceramides.

\section{Ceramides and skin ageing}

Skin changes constitute the first obvious evidence of aging, a complex and multifactorial biological process affecting the whole body. Skin aging is influenced by several factors including genetics, environmental exposure (UV radiation, smoke, pollution...), hormonal changes and metabolic process. These intrinsic and environmental factors gradually make the skin thin, translucent, and more susceptible to trauma and bruise. Aged skin also presents marbled pigmentation, aged spots, loss of elasticity and wrinkles (Gilchrest, 1996).

Histologically, one of the most prominent changes with intrinsic aging is flattening of the dermal-epidermal junction, making it less resistant to shearing forces, as well as decreased thickness of the dermis and the epidermis. Concerning resident cells of the skin other than keratinocytes, a reduced number of melanocytes and Langerhans cells (the epidermal "sentinel" immune cells) have also been described. Comparatively to the dermis and the living layers of the epidermis, little histological changes appear in the stratum corneum of aged skin in comparison to young skin. Notably, it has a virtually normal thickness and basket-weave appearance. Age-dependent functional changes in the stratum corneum have been assessed by measuring different parameters like transcutaneous water loss (transepidermal water loss, TEWL), stratum corneum hydration or skin-surface $\mathrm{pH}$. Some variations in one or more of these parameters were detected in aged skin in comparison to young skin of healthy male and female groups of volunteers, but globally the functionality of the stratum corneum appeared little or non-affected (Leveque et al., 1984; Ghadially et al., 1995; Tagami, 2008; Luebberding et al., 2013, 2014; BoireauAdamezyk et al., 2014). However, when the barrier was experimentally perturbed, for instance with either acetone or tape stripping, it recovered more slowly in aged than in young human subjects (Ghadially et al., 1995). Moreover, it is well documented that aged skin is prone to develop altered drug permeability, increased susceptibility to irritants, contact dermatitis and severe xerosis. Thus the stratum corneum barrier function appears more "fragile" in elderly. Lipids and more particularly ceramide deficiency may account, at least in part, for this dysfunction of the stratum corneum associated with ageing.

A detailed analysis of the effect of aging on the lipid structures in the stratum corneum was performed by the group of P. Elias (Ghadially et al., 1995). They examined by transmission electron microscopy the lipid lamellae and the cornified lipid envelope of young vs. aged skin. In both aged human and mouse epidermis they observed a normal number of lamellar bodies in the granular keratinocytes cytosol, with normal internal structure. However, a paucity of secreted lamellar body contents was present at the stratum granulosum/ stratum corneum interface. Moreover, the stratum corneum interstices contained focal domains that were either depleted or virtually devoid of lamellae. This study was completed by the analysis of lipid content which showed that the quantity of lipids in aged murine stratum corneum was globally reduced ( $\sim 30 \%)$, without exhibiting any specific abnormality in species distribution or fatty acid composition (Ghadially et al., 1995). Significantly decreased levels of all major lipid species, in particular ceramides, with increasing age, were also reported in human (Rogers et al., 1996).

Hence, treatments able to restore skin-ceramide levels and lipid organization in the stratum corneum could improve the epidermal barrier function in aged skin. For some years now many studies have been conducted to identify such treatments. Besides clinical trials performed on aged vs. young subjects (Seyfarth et al., 2011; Danby et al., 2016; Chang et al., 2018), one can also find interesting information from studies done on patients with skin diseases characterized by a perturbation of stratum corneum lipids and a defective barrier, like atopic dermatitis, psoriasis or ichthyoses (Lowe et al., 2012; Liu et al., 2015; Sahle et al., 2015), as well as studies using animal or in vitro models (Di Marzio et al., 2008; Moner et al., 2018; Popa et al., 2018).

Different strategies were developed in order to improve skinceramide levels. One consisted in direct replenishment of the missing lipids or their analogues. Several studies reported positive effects of topically applied preparations containing ceramides on skin barrier function (Kucharekova et al., 2002; Lowe et al., 2012; Liu et al., 2015; Sahle et al., 2015). Importantly, it seems that the therapeutic ceramide may not be applied alone but in combination with other lipids in order to maintain the ratio between the three major lipid components of the stratum corneum. Indeed, partial lipid compositions may result in abnormal lamellar bodies' contents and hence may interfere with the formation of lamellae and cornified lipid envelope. The vehicle used to penetrate the stratum corneum is also important. Efforts are still done in the development of technologies with the aim of highly efficient delivery of the product. For instance, sphingomyelin-based liposomes and lamellar body mimetic system have recently been proposed (Itaya and Tokudome, 2016; Moner et al., 2016). Efficiency of topically applied substitutive lipid mixture may also differ regarding the nature of the topically applied ceramide. Different sources of therapeutic lipids have been proposed, including synthetic or animal-based ceramides as well as plant-derived ceramides (Tessema et al., 2017). Sometimes, therapeutic lipids were administered by oral dietary supplement. Although some clinical studies reported skin-moisturizing and skin barrier recovery effects of such dietary supplement, the fate of the ingested ceramide and the mechanisms underlying skin barrier improvement are still obscure (Tessema et al., 2017). 
Another approach is to facilitate the production of the lipids in vivo. For instance, the administration of agents such as nicotinamide, ascorbic acid and its derivatives, or ursolic acid, a plant-derived triterpenoid, was found to effectively increase the synthesis of epidermal ceramides (Tanno et al., 2000; Yarosh et al., 2000; Katsuyama et al., 2017). Furthermore, the agedependent increase of $\mathrm{pH}$ in the stratum corneum is known to have an impact on the activity of acidic-dependent lipid hydrolases involved in ceramide processing (e.g. $\beta$-glucocerebrosidase, sphingomyelinase). It has been shown that reacidification of the stratum corneum with lacto bionic acid accelerated barrier recovery in old individual and led to increased formation of fully processed lamellae (Choi et al., 2007). In another study, researchers showed that topical application of bacterial sphingomyelinase from Streptococcus thermophilus increased skin-ceramide levels, improved the lipid barrier and augmented a resistance against ageing-associated xerosis in aged subjects (Di Marzio et al., 2008).

\section{Conclusion}

Stratum corneum lipids, and more particularly $\omega-\mathrm{O}-$ acylceramides, play a crucial role in the epidermal barrier function. They are mainly produced by the differentiating living keratinocytes beneath the stratum corneum, undergo extracellular maturation in the lower stratum corneum to finally form extracellular lipid matrix lamellae and cornified lipid envelopes, the two essential lipid structures of the stratum corneum. Clarifying the role of the enzyme PNPLA1, which gene is mutated in some forms of congenital ichthyoses, is a further illustration emphasizing the crucial role of $\omega$-Oacylceramides in the epidermal barrier function. Perturbation of the lipid organization in the stratum corneum is associated with skin conditions of impaired epidermal barrier, including numerous skin diseases (atopic dermatitis, psoriasis, ichthyoses), as well as aged skin in which the permeability barrier is more "fragile". Age-dependent ceramide deficiency contributes to skin fragility in elderly. Restoration of skin-ceramide levels is part of treatments under development for combating the effects of skin aging. Many in vitro, animal and clinical studies are conduced to this end with encouraging and positive results. Continuation of those efforts and further experiments are needed to improve such treatments and better understand the underlying molecular mechanisms of lipid barrier restoration.

Acknowledgements. The author wishes to thank the staff of the lab "Epithelial Differentiation and Rheumatoid Autoimmunity" and more particularly Mélanie Pichery who was heavily involved in the work on PNPLA1. N.J. gratefully acknowledges support for the research project on PNPLA1 provided by PHENOMIN and the Société Française de Dermatologie.

Conflicts of interest. The author declares that she has no conflicts of interest in relation to this article.

\section{References}

Boireau-Adamezyk E, Baillet-Guffroy A, Stamatas GN. 2014. Agedependent changes in stratum corneum barrier function. Skin Res Technol 20(4): 409-15.
Borodzicz S, Rudnicka L, Mirowska-Guzel D, Cudnoch-Jedrzejewska A. 2016. The role of epidermal sphingolipids in dermatologic diseases. Lipids Health Dis 15(1): 13.

Breiden B, Sandhoff K. 2014. The role of sphingolipid metabolism in cutaneous permeability barrier formation. Biochim Biophys Acta 1841(3): 441-52.

Castiel-Higounenc I, Chopart M, Ferraris C. 2004. Stratum corneum lipids: Specificity, role, deficiencies and modulation. OCL 11(6): 401.

Chang ALS, Chen SC, Osterberg L, Brandt S, von Grote EC, Meckfessel MH. 2018. A daily skincare regimen with a unique ceramide and filaggrin formulation rapidly improves chronic xerosis, pruritus, and quality of life in older adults. Geriatr Nurs 39(1): 24-8.

Choi EH, Man MQ, Xu P et al. 2007. Stratum corneum acidification is impaired in moderately aged human and murine skin. $J$ Invest Dermatol 127(12): 2847-56.

Danby SG, Brown K, Higgs-Bayliss T, Chittock J, Albenali L, Cork MJ. 2016. The effect of an emollient containing urea, ceramide $\mathrm{NP}$, and lactate on skin barrier structure and function in older people with dry skin. Skin Pharmacol Physiol 29(3): 135-47.

Di Marzio L, Cinque B, Cupelli F, De Simone C, Cifone MG, Giuliani M. 2008. Increase of skin-ceramide levels in aged subjects following a short-term topical application of bacterial sphingomyelinase from Streptococcus thermophilus. Int J Immunopathol Pharmacol 21(1): 137-43.

Elias PM, Williams ML, Holleran WM, Jiang YJ, Schmuth M. 2008. Pathogenesis of permeability barrier abnormalities in the ichthyoses: Inherited disorders of lipid metabolism. J Lipid Res 49(4): 697-714.

Epp N, Furstenberger G, Muller K et al. 2007. 12R-lipoxygenase deficiency disrupts epidermal barrier function. J Cell Biol 177(1): 173-82.

Ghadially R, Brown BE, Sequeira-Martin SM, Feingold KR, Elias PM. 1995. The aged epidermal permeability barrier. Structural, functional, and lipid biochemical abnormalities in humans and a senescent murine model. J Clin Invest 95(5): 2281-90.

Gilchrest BA. 1996. A review of skin ageing and its medical therapy. Br J Dermatol 135(6): 867-75.

Grall A, Guaguere E, Planchais S et al. 2012. PNPLA1 mutations cause Autosomal Recessive Congenital Ichthyosis in golden retriever dogs and humans. Nat Genet 44(2): 140-7.

Grond S, Eichmann TO, Dubrac S et al. 2017. PNPLA1 deficiency in mice and humans leads to a defect in the synthesis of omega-Oacylceramides. J Invest Dermatol 137(2): 394-402.

Herrmann T, Grone HJ, Langbein L et al. 2005. Disturbed epidermal structure in mice with temporally controlled fatp4 deficiency. $J$ Invest Dermatol 125(6): 1228-35.

Hirabayashi T, Anjo T, Kaneko A et al. 2017. PNPLA1 has a crucial role in skin barrier function by directing acylceramide biosynthesis. Nat Commun 8: 14609.

Itaya Y, Tokudome Y. 2016. Upregulation of gene expression levels of ceramide metabolic enzymes after application of sphingomyelinbased liposomes to a three-dimensional cultured human epidermis model. Biochem Biophys Res Commun 473(1): 114-7.

Jennemann R, Sandhoff R, Langbein L et al. 2007. Integrity and barrier function of the epidermis critically depend on glucosylceramide synthesis. J Biol Chem 282(5): 3083-94.

Jennemann R, Rabionet M, Gorgas K et al. 2012. Loss of ceramide synthase 3 causes lethal skin barrier disruption. Hum Mol Genet 21 (3): 586-608.

Katsuyama Y, Taira N, Tsuboi T, Yoshioka M, Masaki H, Muraoka O. 2017.3-O-Laurylglyceryl ascorbate reinforces skin barrier function through not only the reduction of oxidative stress but also the activation of ceramide synthesis. Int J Cosmet Sci 39(1): 49-55.

Kienesberger PC, Oberer M, Lass A, Zechner R. 2009. Mammalian patatin domain containing proteins: A family with diverse 
lipolytic activities involved in multiple biological functions. J Lipid Res 50: S63-8.

Krieg P, Rosenberger S, de Juanes S et al. 2013. Aloxe3 knockout mice reveal a function of epidermal lipoxygenase-3 as hepoxilin synthase and its pivotal role in barrier formation. $J$ Invest Dermatol 133(1): 172-80.

Kucharekova M, Schalkwijk J, Van De Kerkhof PC, Van De Valk PG. 2002. Effect of a lipid-rich emollient containing ceramide 3 in experimentally induced skin barrier dysfunction. Contact Dermatitis 46(6): 331-8.

Leveque JL, Corcuff P, de Rigal J, Agache P. 1984. In vivo studies of the evolution of physical properties of the human skin with age. Int J Dermatol 23(5): 322-9.

Li W, Sandhoff R, Kono M et al. 2007. Depletion of ceramides with very long chain fatty acids causes defective skin permeability barrier function, and neonatal lethality in ELOVL4 deficient mice. Int J Biol Sci 3(2): 120-8.

Liu M, Li X, Chen XY, Xue F, Zheng J. 2015. Topical application of a linoleic acid-ceramide containing moisturizer exhibit therapeutic and preventive benefits for psoriasis vulgaris: A randomized controlled trial. Dermatol Ther 28(6): 373-82.

Lowe AJ, Tang ML, Dharmage SC et al. 2012. A phase I study of daily treatment with a ceramide-dominant triple lipid mixture commencing in neonates. BMC Dermatol 12: 3.

Luebberding S, Krueger N, Kerscher M. 2013. Age-related changes in skin barrier function-Quantitative evaluation of 150 female subjects. Int J Cosmet Sci 35(2): 183-90.

Luebberding S, Krueger N, Kerscher M. 2014. Age-related changes in male skin: Quantitative evaluation of one hundred and fifty male subjects. Skin Pharmacol Physiol 27(1): 9-17.

Matsuki M, Yamashita F, Ishida-Yamamoto A et al. 1998. Defective stratum corneum and early neonatal death in mice lacking the gene for transglutaminase 1 (keratinocyte transglutaminase). Proc Natl Acad Sci USA 95(3): 1044-9.

Menon GK, Cleary GW, Lane ME. 2012. The structure and function of the stratum corneum. Int J Pharm 435(1): 3-9.

Moner V, Fernandez E, Rodriguez G et al. 2016. Lamellar body mimetic system: An up-to-down repairing strategy of the stratum corneum lipid structure. Int J Pharm 510(1): 135-43.

Moner V, Fernandez E, Calpena AC, Garcia-Herrera A, Cocera M, Lopez O. 2018. A lamellar body mimetic system for the treatment of oxazolone-induced atopic dermatitis in hairless mice. J Dermatol Sci 90(2): 172-9.

Motta S, Monti M, Sesana S, Caputo R, Carelli S, Ghidoni R. 1993. Ceramide composition of the psoriatic scale. Biochim Biophys Acta 1182(2): 147-51.

Moulson CL, Lin MH, White JM, Newberry EP, Davidson NO, Miner JH. 2007. Keratinocyte-specific expression of fatty acid transport protein 4 rescues the wrinkle-free phenotype in Slc27a4/Fatp4 mutant mice. J Biol Chem 282(21): 15912-20.

Ohno Y, Nakamichi S, Ohkuni A et al. 2015. Essential role of the cytochrome P450 CYP4F22 in the production of acylceramide, the key lipid for skin permeability barrier formation. Proc Natl Acad Sci USA 112(25): 7707-12.

Ohno Y, Kamiyama N, Nakamichi S, Kihara A. 2017. PNPLA1 is a transacylase essential for the generation of the skin barrier lipid omega-O-acylceramide. Nat Commun 8: 14610.
Ohno Y, Nara A, Nakamichi S, Kihara A. 2018. Molecular mechanism of the ichthyosis pathology of Chanarin-Dorfman syndrome: Stimulation of PNPLA1-catalyzed omega-O-acylceramide production by ABHD5. J Dermatol Sci 92(3): 245-53.

Pichery M, Huchenq A, Sandhoff R et al. 2017. PNPLA1 defects in patients with autosomal recessive congenital ichthyosis and $\mathrm{KO}$ mice sustain PNPLA1 irreplaceable function in epidermal omega$\mathrm{O}$-acylceramide synthesis and skin permeability barrier. Hum Mol Genet 26(10): 1787-800.

Popa I, Watson AL, Solgadi A, Butowski C, Allaway D, Portoukalian J. 2018. Linoleate-enriched diet increases both linoleic acid esterified to omega hydroxy very long chain fatty acids and free ceramides of canine stratum corneum without effect on proteinbound ceramides and skin barrier function. Arch Dermatol Res 310(7): 579-89.

Rabionet M, Gorgas K, Sandhoff R. 2014. Ceramide synthesis in the epidermis. Biochim Biophys Acta 1841(3): 422-34.

Rogers J, Harding C, Mayo A, Banks J, Rawlings A. 1996. Stratum corneum lipids: The effect of ageing and the seasons. Arch Dermatol Res 288(12): 765-70.

Sahle FF, Gebre-Mariam T, Dobner B, Wohlrab J, Neubert RH. 2015. Skin diseases associated with the depletion of stratum corneum lipids and stratum corneum lipid substitution therapy. Skin Pharmacol Physiol 28(1): 42-55.

Schiller SA, Seebode C, Wieser GL et al. 2016. Establishment of two mouse models for CEDNIK syndrome reveals the pivotal role of SNAP29 in epidermal differentiation. J Invest Dermatol 136(3): 672-9.

Seyfarth F, Schliemann S, Antonov D, Elsner P. 2011. Dry skin, barrier function, and irritant contact dermatitis in the elderly. Clin Dermatol 29(1): 31-6.

Smyth I, Hacking DF, Hilton AA et al. 2008. A mouse model of harlequin ichthyosis delineates a key role for Abca12 in lipid homeostasis. PLoS Genet 4(9): e1000192.

Tagami H. 2008. Functional characteristics of the stratum corneum in photoaged skin in comparison with those found in intrinsic aging. Arch Dermatol Res 300(1): S1-6.

Tanno O, Ota Y, Kitamura N, Katsube T, Inoue S. 2000. Nicotinamide increases biosynthesis of ceramides as well as other stratum corneum lipids to improve the epidermal permeability barrier. Br J Dermatol 143(3): 524-31.

Tessema EN, Gebre-Mariam T, Neubert RHH, Wohlrab J. 2017. Potential applications of phyto-derived ceramides in improving epidermal barrier function. Skin Pharmacol Physiol 30(3): 115-38.

Toulza E, Mattiuzzo NR, Galliano MF et al. 2007. Large-scale identification of human genes implicated in epidermal barrier function. Genome Biol 8(6): R107.

van Smeden J, Janssens M, Gooris GS, Bouwstra JA. 2014. The important role of stratum corneum lipids for the cutaneous barrier function. Biochim Biophys Acta 1841(3): 295-313.

Wilson PA, Gardner SD, Lambie NM, Commans SA, Crowther DJ. 2006. Characterization of the human patatin-like phospholipase family. J Lipid Res 47(9): 1940-9.

Yarosh DB, Both D, Brown D. 2000. Liposomal ursolic acid (merotaine) increases ceramides and collagen in human skin. Horm Res 54(5-6): 318-21.

Cite this article as: Jonca N. 2019. Ceramides metabolism and impaired epidermal barrier in cutaneous diseases and skin aging: focus on the role of the enzyme PNPLA1 in the synthesis of $\omega$-O-acylceramides and its pathophysiological involvement in some forms of congenital ichthyoses. $O C L$ 26: 17. 